\title{
Grounding Impedance Characteristics for Two-Layer Soil of Vertical Rod Configuration with Variation of Length and Diameter
}

\author{
Bambang Anggoro ${ }^{1}$, Rio Hakim Dharmawanwas ${ }^{2}$, Hanifah Nur Kumala Ningrum ${ }^{3}$, \\ Junaidy Burhan ${ }^{4}$, and Mohamad Rom bin Tamjis ${ }^{5}$ \\ ${ }^{1}$ School of Electrical Engineering and Informatics, Bandung Institute of Technology \\ ${ }^{2}$ Sultan Aji Muhammad Sulaiman International Airport, Sepinggan Balikpapan \\ ${ }^{3}$ State Polytechnic of Madiun, East Java \\ ${ }^{4}$ Polytechnic Engineering Indorama of Purwakarta, West Java \\ ${ }^{5}$ Faculty of Engineering, Malaya University - Malaysia \\ b.anggoro55@gmail.com, bambanga@hv.ee.itb.ac.id
}

\begin{abstract}
Grounding impedance is an important component of electrical power systems especially for protection for human safety and the continuity of the operation of power systems. At low frequency current injection the characteristics of grounding impedance is very resistive, however at high frequency it may be capacitive or inductive depending on the frequency. In order to build a grounding system used for lightning protection, it needs a careful and accurate design. It will receive high current and high frequency around hundred kilos up to mega hertz, otherwise it is simple grounding for low frequency. This paper reports the modification of a grounding system with vertical layers configuration. This is the novel issue because the other researchers use horizontal layers configuration. In this experiment, the grounding rod is injected by using low to high frequency AC source The modification is made by filling the soil into a grounding rod (cylinder rod) and therefore it created two soil layers of grounding system, and by using three size variations of cylindrical layers of length (L) of 40, 60, and $100 \mathrm{~cm}$; and three size variations of diameter (D) of 20, 30, and $40 \mathrm{~cm}$. These variations will allow us to understand the characteristic of the grounding impedance at low and high frequency, where usually the composition of inner layer soil have lower resistance than the outer soil. The composition of the outer soil consist of $16.85 \%$ clay, 66.18 $\%$ silt, $15.48 \%$ sand, and $1.49 \%$ gravel whereas the composition for the inner/filling soil consist of $34.98 \%$ clay, $49.55 \%$ silt, $15.35 \%$ sand, and $0.16 \%$ gravel. The value of soil permittivity and resistivity affect the value of grounding impedance at low and high frequency. In general, the results indicated that the grounding impedance at high frequency was higher than at low frequency, but the fluctuation of grounding impedance depended on the condition of inner soil, length and diameter of cylindrical rod. In this research, the grounding impedance was plotted as the function of the frequency and until now the value of this fluctuation cannot be determined accurately.
\end{abstract}

Keywords: grounding impedance, vertical grounding system; soil resistivity; type of soil; soil permittivity

\section{Introduction}

Electrical grounding system is the simple component in a power system, yet it plays a very urgent and important role in protecting human, equipment, and system safety. NEC defines grounding system as "a relationship (conduction) either intentionally or unintentionally between the electrical circuit and the ground or connect with conductive objects that are on the ground". The grounding impedance depends on the shape and the quantity of current injection, material condition of soil, and grounding configurations [1]. The environment condition determines the grounding configuration design, where in arid or dry soil condition the grounding impedance is usually high. This problem can be solved by modifying the configuration of the grounding system or by treating the soil [2]. The grounding impedance is influenced by several factors,

Received: July $23^{\text {th }}, 2017$. Accepted: December $30^{\text {th }}, 2018$

DOI: 10.15676/ijeei.2018.10.4.12 
which are a) electrodes configuration, b) material composition of soil, and c) shape of current injection. So the general function of grounding impedance is [3]:

$$
\mathrm{Z}=\mathrm{Z}(\mathrm{C}, \mathrm{S}, \mathrm{I},)
$$

Where $\mathrm{Z}$ : grounding impedance

C: electrodes configuration (vertical, horizontal, grid or mesh, and combination of grid vertical)

S: soil material composition (resistivity $\rho$, permittivity $\varepsilon$, permeability $\mu$ )

I: injected current shape (DC, AC or impulse current)

The electrode configuration depends on the soil surface. For narrow soil, the electrode configuration is made by using vertical configuration. For wide soil, the configuration is designed using horizontal or grid configuration. The horizontal or grid grounding impedance has a more stable value than the vertical configuration because the area of grounding space is very large[4].

The electric constants of soil such as resistivity $\rho$, permittivity $\varepsilon$, and permeability $\mu$ depend on the type of soil such as clay, silt, sand, and gravel. These electric constants of different types of soils will be tested to understand its impact to the grounding impedance.

Furthermore, the type of injected current such as DC, impulse, or AC with variety of frequency, affects the grounding impedance. The grounding system used in the power system must be tested using DC or AC with low frequency. The grounding system used for lightning protection must be tested by using impulse or AC with high frequency. It is known that lightning current has high frequency up to mega hertz.

The grounding impedance may be reduced by lengthen the grounding rod. It reduces the resistance but increase the inductance of the grounding rod. The grounding impedance may also be reduced by enlarging the rod diameter. It can be made by modifying the grounding rod with two layers of soil, where the resistivity of inner layer is lower than one of outer layer. In this experiment, the grounding rod is injected by using low to high frequency AC source $[5,6]$.

According to IEEE standard 142-2007 [7-10], the impedance grounding system are proposed for:

a. The current flow of undesirable conduction between grounding systems and conductor must be provided.

b. The permitted potential between earths to boundary must be limited.

c. The value of the grounding impedance needs to be as low as possible.

Transient voltage and electric shock commonly are caused by electrostatic discharge, short circuit, and circuit switching. An effective grounding system can minimize these effects, and grounding system must comply with these requirements $[8,10]$.

a. Use noncorrosive materials of soil and chemical to ensure equipment long-life time.

b. Low impedance path from ground to equipment safety must be effective.

c. Mechanical system is used to repair and maintain when damage happens.

d. The spread of fault and surge current must be detected accurately and timely

e. Large grounding system must be protected physically.

This paper reports the modification of a grounding system with vertical layers configuration. This is the novel issue because the other researchers use horizontal layers configuration. In this experiment, the grounding rod is injected by using low to high frequency AC source The modification is made by filling the soil into a grounding rod (cylinder rod) and therefore it created two soil layers of grounding system, and by using three size variations of cylindrical layers of length (L) of 40, 60, and $100 \mathrm{~cm}$; and three size variations of diameter (D) of 20,30, and $40 \mathrm{~cm}$. These variations will allow us to understand the characteristic of the grounding impedance at low and high frequency, where usually the composition of inner layer soil have lower resistance than the outer soil. The composition of the outer soil consist of $16.85 \%$ clay, $66.18 \%$ silt, 15.48 
$\%$ sand, and $1.49 \%$ gravel whereas the composition for the inner/filling soil consist of $34.98 \%$ clay, $49.55 \%$ silt, $15.35 \%$ sand, and $0.16 \%$ gravel.

\section{Theory}

Grounding system has three functions which are: (1) for power systems divided into two points (1a) neutral system, (1b) conductive of electric equipment body; (2) lightning protection, and (3) high frequency equipment [6]. All of these grounding systems must be able to flow currents effectively to the ground when fault occurs in a power system.

The grounding impedance is different when it is injected at low and high frequency, where the impedance is higher at high frequency than when it is at lower frequency because the induction of grounding system more dominant than the resistance, and the equivalent circuit is not only resistance but also inductance and capacitance. Dawalibi and Mukedarhad propose for the equivalent circuit of grounding systems for high frequency design as can be seen in Figure 1. [11 - 13]

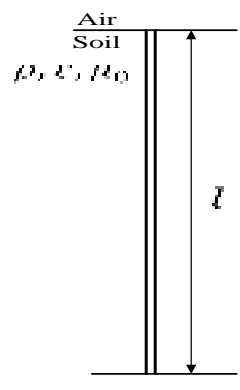

(a)

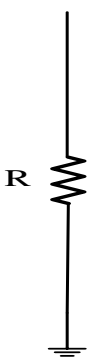

(b)

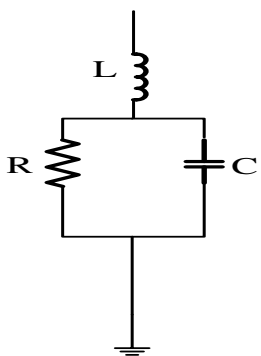

(c)

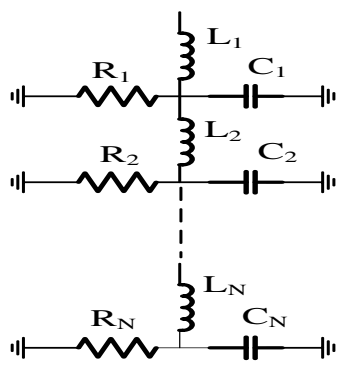

(d)

Figure 1(a) Grounding electrode, (b) Equivalent circuit on low frequency, (c) Equivalent circuit on high frequency, (d) Distribution parameters on high frequency [12]

If grounding rod is injected by high frequency current, the equivalent circuit must consist of inductor (L) series with resistor (R) and paralleled with capacitor (C), as can be seen in Figure 1(c) and Figure 1(d) for distributed equivalent circuit. Leonid Grcev proposes the following formula for calculating the value of R, C, and L in Equation (2) to (4) [15].

$$
\begin{aligned}
R & =\frac{\rho}{2 \pi l} \log \frac{2 l}{r} \\
C & =\frac{2 \pi \varepsilon_{0} \varepsilon_{r} l}{\log \frac{2 l}{r}} \\
L & =\frac{\mu_{0} l}{2 \pi} \log \frac{2 l}{r}
\end{aligned}
$$

Where:

$\mathrm{R}=$ soil resistance $(\Omega)$

$\rho=$ soil resistivity $(\Omega . m)$

$\mathrm{C}=$ soil capacitance $(\mathrm{F})$

$\varepsilon_{0}=$ permittivity $(\mathrm{F} / \mathrm{m})$

$\mathrm{L}=$ soil inductance $(\mathrm{H})$

$\varepsilon_{\mathrm{r}}=\operatorname{soil}$ permittivity $(\mathrm{F} / \mathrm{m})$

$\mu_{0}=$ permeability $(\mathrm{H} / \mathrm{m})$

$l=$ length of electrode $(\mathrm{m})$

$\mathrm{r}=$ radius of electrode $(\mathrm{m})$

Figure 1(c) and 1(d) are the equivalent circuits specifically for high frequency where frequency for Figure 1(c) is less than Figure 1 (d) and the frequency border between these circuits are about $100 \mathrm{kHz}$, this is because at frequency more than $100 \mathrm{kHz}$ the response of grounding 
impedance fluctuates towards frequency change, hence the equivalent circuit is distributed with several peaks at its resonance frequency.

RLC Formulation for 2 Layers Ground Rod

Calculation of R, L, C for 2 layers ground rod can be calculated using formula on Figure 2.

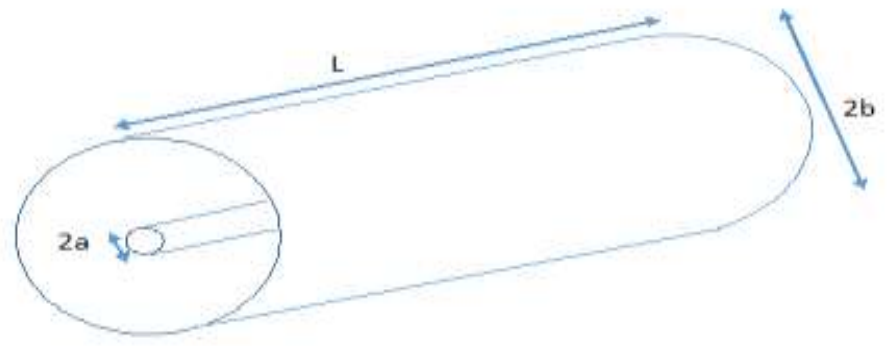

Figure 2. Two-cylinderModel[7]

$$
\begin{aligned}
R & =\frac{\rho}{2 \pi l} \ln \frac{b}{a} \\
C & =\varepsilon_{0} \varepsilon_{r} \frac{2 \pi l}{\ln \frac{b}{a}} \\
L & =\frac{\mu_{0} l}{\pi} \ln \frac{b}{a}
\end{aligned}
$$

Where:

$\mathrm{R}=$ soil resistance $(\Omega)$

$\mathrm{C}=$ soil capacitance $(\mathrm{F})$

$\mathrm{L}=$ soil inductance $(\mathrm{H})$

$\rho=$ soil resistivity $(\Omega \mathrm{m})$

$\varepsilon_{0}=$ permittivity $(\mathrm{F} / \mathrm{m})$

$\mathrm{b}=$ radius of outer cylinder $(\mathrm{m})$

$\varepsilon_{\mathrm{r}}=$ soil permittivity $(\mathrm{F} / \mathrm{m})$

$\mathrm{a}=$ radius of inner cylinder $(\mathrm{m})$

$\mu_{0}=$ air permeability $(\mathrm{H} / \mathrm{m})$

$l=$ length of electrode $(\mathrm{m})$

Based on the equivalent circuit of grounding systems (figure 1c above) the impedance characteristics can be expressed by the equation below .

$$
\begin{aligned}
& Z=j \cdot \omega \cdot L+\left(\frac{R / j \cdot \omega \cdot C}{R+1 / j \cdot \omega \cdot C}\right) \\
& Z=\frac{R}{1+[\omega \cdot R \cdot C]^{2}}+j \varpi\left\{\frac{L-R^{2} C+(\omega \cdot R \cdot C)^{2} L}{1+[\omega \cdot R \cdot C]^{2}}\right\} \\
& Z \cdot \cos \varphi=\frac{R}{1+[\omega \cdot R \cdot C]^{2}} \\
& Z \cdot \sin \varphi=j \cdot \omega \cdot\left\{\frac{L-R^{2} C+(\omega \cdot R \cdot C)^{2} L}{1+[\omega \cdot R \cdot C]^{2}}\right\} .
\end{aligned}
$$

Above equation can be explained as when the injection of current frequency is very low or equal to zero (Direct Current) then the grounding impedance is:

$$
Z_{0}=R_{0}
$$

And at resonance frequency, only the real component of impedance is a dominance but not at zero frequency ( $\mathrm{f}=0$ ), so the grounding impedance is : 


$$
Z=\frac{R}{1+[\varpi R C]^{2}}
$$

The resonance frequency will occur if the imaginary component of impedance $=0$

$$
\begin{aligned}
& L-R^{2} C+\{\omega \cdot R \cdot C\}^{2} L=0 \\
& \omega^{2}=\frac{R^{2} C-L}{(R C)^{2} L} \\
& f r=\frac{1}{2 \pi} \sqrt{\frac{R^{2} C-L}{(R C)^{2} L}} .
\end{aligned}
$$

From these equations can be explained that :

$$
L+\{\omega \cdot R \cdot C\}^{2} L-R^{2} C=0
$$

The grounding impedance $\mathrm{Z}_{(\mathrm{f})}$ act as an inductive if:

$$
\begin{aligned}
& L\left[1+\{\omega \cdot R \cdot C\}^{2}\right]-R^{2} C>0 \\
& L>\frac{R^{2} C}{\left[1+\{\omega \cdot R \cdot C\}^{2}\right]}
\end{aligned}
$$

The grounding impedance $\mathrm{Z}_{(\mathrm{f})}$ act as a capacitive if:

$$
L<\frac{R^{2} C}{\left[1+\{\omega \cdot R \cdot C\}^{2}\right]}
$$

c) And the grounding impedance $Z_{(\mathrm{f})}$ act as a resistive, but not the same as resistance $R$ if:

$$
L=\frac{R^{2} C}{\left[1+\{\omega \cdot R \cdot C\}^{2}\right]}
$$

In low-frequency and domain the DC field, only soil conductivity must be studied. However, the influence of soil permittivity on ground potential distribution increases as the frequency increases. So an accurate soil model should include soil permittivity that are frequency dependent, which means their values are varied with frequency.It has been verified that ColeCole model can describe soil complex resistivity or complex conductivity observed soil [16$18]$.

\section{Experiments}

The purpose of the modification of the grounding rod system with two layers of different soils is to make the grounding impedance to be always low at all frequencies. The two layers of different soils used in this experiment are called as Soil Sample 1 and Soil Sample 2.

The combination of inner soil layer which has lower resistivity and outer soil layers and different dimension of rods (diameter and length) on vertical rod of grounding system are expected to reduce the grounding impedance.

The resistivity and permeability of soil depends on the type and the micro structure of the soil itself. Therefore, these parameters were examined before it was used for the grounding purpose.

\section{A. Soil Samples and Analysis of Soil Characteristics with Index Properties and Grain Size}

Table 1 shows the properties of soil sample 1 and soil sample 2. Saturated soil with a void ratio greater than 1.0 contains a greater volume of water than soil. The emphasis of soil 
composition and properties study has been almost entirely on the mineralogy and structure of the soil phase, with very little regard for the properties of the liquid phase. The properties and structure of water in soil are not well known in detail, there is no rigorous theory for the structure of pure, liquid water, only a hypothesis. Since neither water nor soil surface are inert chemically, water and soil particles interact with each other. These interactions can be expected to influence the physical and physical-chemical behaviour of the material.

Table 1. Properties of Soil Sample 1 and Soil Sample 2

\begin{tabular}{|c|c|c|c|}
\hline No. & Parameters & Soil sample 1 & Soil sample 2 \\
\hline 1. & Water content & $48,27 \%$ & $41,62 \%$ \\
\hline 2. & Wet density $\left(\gamma_{\mathrm{w}}\right)$ & $1,69 \mathrm{t} / \mathrm{m}^{3}$ & $1,73 \mathrm{t} / \mathrm{m}^{3}$ \\
\hline 5. & Dry density $\left(\gamma_{\mathrm{d}}\right)$ & $1,14 \mathrm{t} / \mathrm{m}^{3}$ & $1,22 \mathrm{t} / \mathrm{m}^{3}$ \\
\hline 6. & Specific gravity $\left(\mathrm{G}_{\mathrm{s}}\right)$ & 2,59 & 2,54 \\
\hline 7. & void Ratio $(\mathrm{e})$ & 1,27 & 1,08 \\
\hline 8. & Porosity $(\mathrm{n})$ & 0,56 & 0,52 \\
\hline 9. & Saturation Degree & $98,29 \%$ & $97,96 \%$ \\
\hline
\end{tabular}

Table 2 shows the grain size of Soil Sample 1 and Soil Sample 2. Clays are small crystalline particles of one or more member of small group of minerals. They are primarily hydrous aluminium silicate with magnesium or iron occupying all or parts of the aluminium position in some minerals with alkalis (sodium, potassium) or alkaline earth (calcium, magnesium). Colloid chemistry provides a means for description of interaction in clay-water-electrolyte systems, and make distribution of cations and anions adjacent to clay surface, like capacitor in electrical circuit. [19].

Table 2. Grain size of Soil Sample 1 and Soil Sample 2

\begin{tabular}{|c|ll|c|c|}
\hline No. & \multicolumn{2}{|c|}{ Size Category } & Soil Sample 1 & Soil Sample 2 \\
\hline 1. & Clay $\quad(<0.005 \mathrm{~mm})$ & $16,85 \%$ & $34,98 \%$ \\
\hline 2. & Silt $(0.005-0.075 \mathrm{~mm})$ & $66,18 \%$ & $49,55 \%$ \\
\hline 3. & Sand $(0.075-4.75 \mathrm{~mm})$ & $15,48 \%$ & $15,35 \%$ \\
\hline 4. & Gravel $(>4.75 \mathrm{~mm})$ & $1,49 \%$ & $0,16 \%$ \\
\hline
\end{tabular}

Clays are small crystalline particles of one or more member of small group of minerals. They are primarily hydrous aluminium silicate with magnesium or iron occupying all or parts of the aluminium position in some minerals with alkalis (sodium, potassium) or alkaline earth (calcium, magnesium). Colloid chemistry provides a means for description of interaction in clay-waterelectrolyte systems, and make distribution of cations and anions adjacent to clay surface, like capacitor in electrical circuit. [19]. According to Porkomenkothat the permittivity of soil and water can be expressed by this equation [20]:

$$
\varepsilon_{r}=(1-\phi) \varepsilon_{m}+\phi \quad \varepsilon_{w}
$$

Where: $\varepsilon_{r}=$ Soil dielectric Constanta; $\varepsilon_{m}=$ Material dielectric Constanta

$\varepsilon_{w}=$ Water dielectric Constanta; $\phi \quad=$ Porosity of soil

Permittivity value of soil as the function of frequency can be expressed like the equation below $\varepsilon=\varepsilon^{\prime}+\mathrm{j} \varepsilon "$ 
Figure 3 explains that material (soil) at high frequency have soil permittivity $\varepsilon^{\prime}$ and $\varepsilon$ " as a function of frequency where the phase angle between $\varepsilon^{\prime}$ and $\varepsilon^{\prime \prime}$ is $90^{\circ}$, so if $\varepsilon^{\prime}$ as reactive impedance and $\varepsilon$ " as resistive impedance then the resistive at low frequency is not the same when at high frequency. To understand more in detail the value of these active and reactive impedance the properties and characteristics of soil at high frequency must be well-known

Non-clay (silt, sand and gravel) soil contributes to electrical conduction with different characteristics, while the permeability relatively constant.

So, type of soil 1 is silt loam soil and type of soil 2 is silt clay loam. Based on IEEE standard 142-1991 about soil resistivity value, resistivity value of soil 1 (Outer Layer) is 200-400 ohm$\mathrm{m}$. Soil 2 (Inner Layer) has resistivity value is $50-100 \mathrm{ohm}-\mathrm{m}$. The resistivity and permittivity of soil is the function of the injected current frequency [21,22,]

\section{B. Experimental Setup: Measurement of Grounding System Impedance}

This experiment contains the modification of a grounding system with vertical layers configuration. In this experiment, the grounding rod is injected by using low to high frequency AC source. The modification is made by filling the soil into a grounding rod (cylinder rod) and therefore it created two soil layers of grounding system, and by using three size variations of cylindrical layers of length (L) of 40,60, and $100 \mathrm{~cm}$; and three size variations of diameter (D) of 20,30 , and $40 \mathrm{~cm}$. These variations will allow us to understand the characteristic of the grounding impedance at low and high frequency, where usually the composition of inner layer soil has lower resistance than the outer soil. Figure 3 shows grounding rod configuration inside soil layer with various diameter. Figure 4 shows photograph of grounding rod inside soil layer. The composition of the outer soil (Soil Sample 1) consist of $16.85 \%$ clay, $66.18 \%$ silt, $15.48 \%$ sand, and $1.49 \%$ gravel whereas the composition for the inner/filling soil (Soil Sample 2) consist of $34.98 \%$ clay, $49.55 \%$ silt, $15.35 \%$ sand, and $0.16 \%$ gravel.
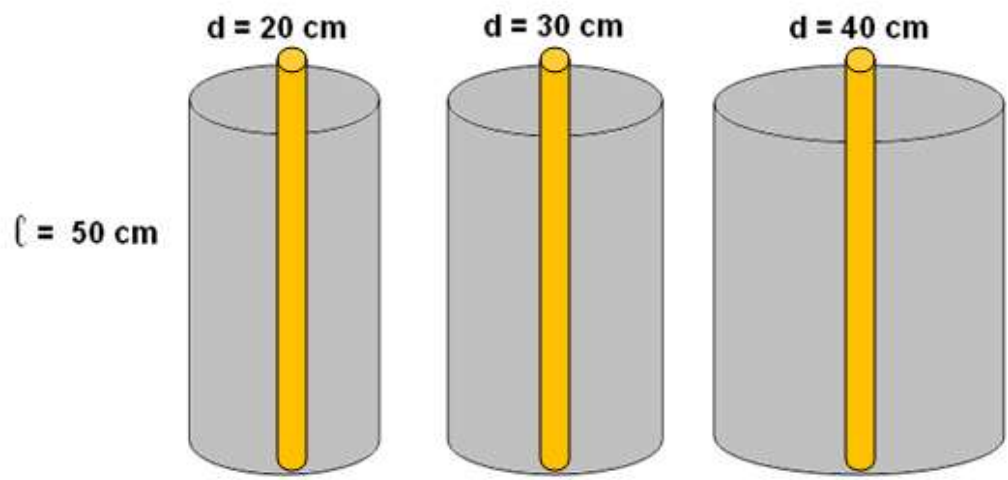

Figure 3. Grounding rod configuration inside soil layer with various diameter

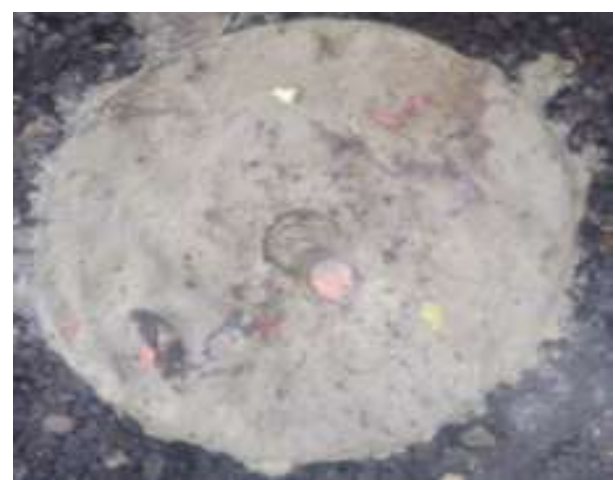

Figure 4. Photograph of grounding rod inside soil layer 
Figure 5 shows experimental setup of the measurement of grounding rod impedance with two layers soils by using three points method. $\mathrm{C} 0$ is a tube as the grounding rod with $20 \mathrm{~cm}, 30 \mathrm{~cm}$, and $40 \mathrm{~cm}$ in diameter and $50 \mathrm{~cm}$ in length (b). $\mathrm{C} 1$ and $\mathrm{C} 2$ are the electrodes made from the copper with $\mathrm{a}=30 \mathrm{~cm}$ in length. The distance of $\mathrm{C} 0-\mathrm{C} 1(6.2$ meter $)$ is $62 \%$ of the distance of $\mathrm{C} 0-\mathrm{C} 2$ (10 meter).

The measurement system consist of the tube, the function generator, oscilloscope, the elektrodes, and resistor $(\mathrm{R}=1 \mathrm{k} \mathrm{ohm})$. The function generator injects current to the grounding measurement system with the $1 \mathrm{~Hz}-15 \mathrm{MHz}$ in frequency and $10 \mathrm{Vpp}$ in voltage. The channel 1 of the oscilloscope displays the voltage of $\mathrm{R}\left(\mathrm{V}_{1}\right)$. The channel 2 displays the potential difference between $\mathrm{C} 0$ and $\mathrm{C} 2\left(\mathrm{~V}_{2}\right)$. The phase angle between $\mathrm{V} 1$ and $\mathrm{V} 2$ is the phase angle between signals measured in Channel 1 and Channel 2. The current $(\mathrm{I})$ is obtained from $\mathrm{I}=\frac{\mathrm{V}_{1}}{\mathrm{R}}$. The voltage $(\mathrm{V})$ is obtained from $V_{2}$, so $V=V_{2}$. Therefore, the impedance of grounding system is $Z=\frac{V}{I}$.

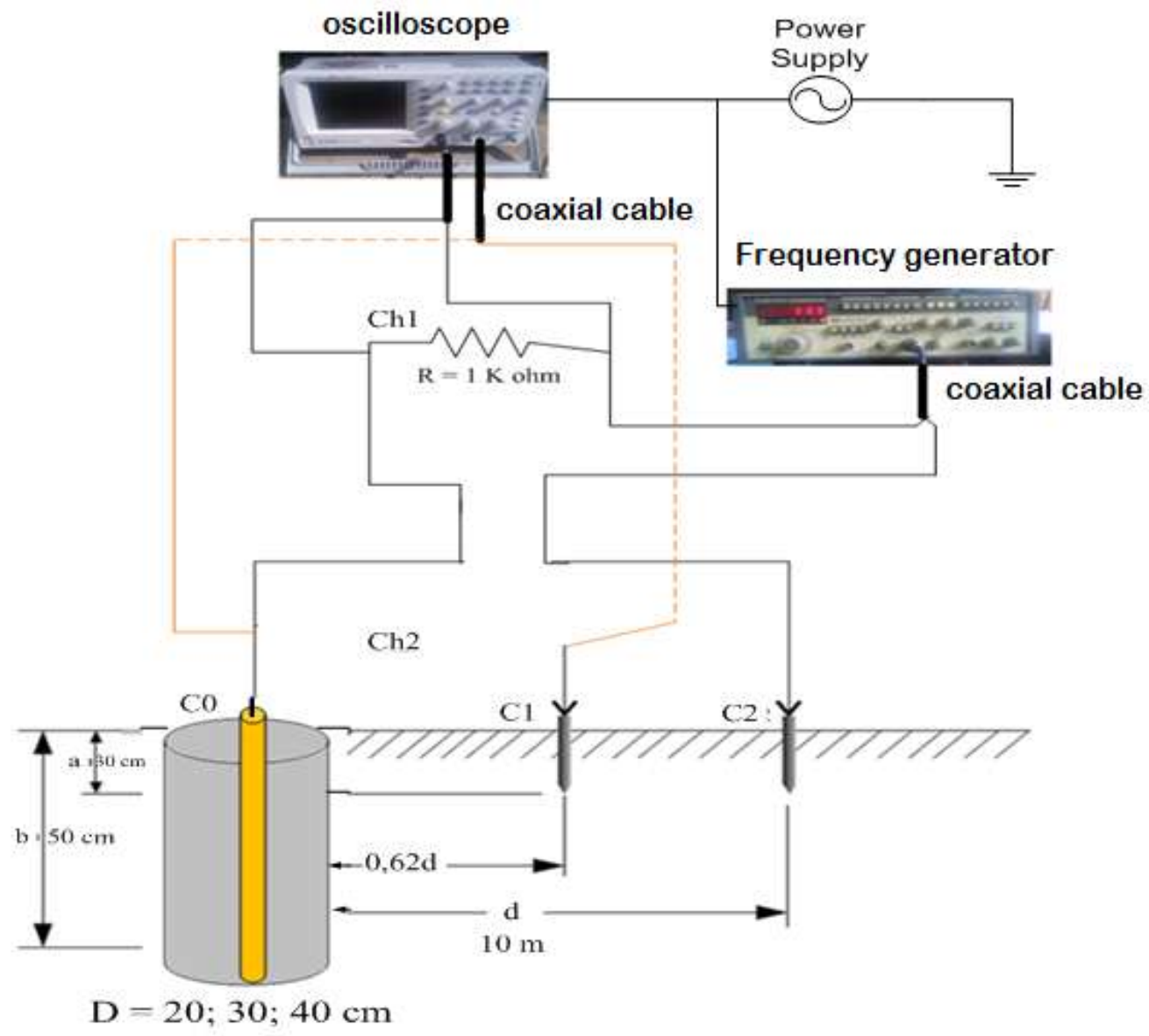

Figure 5. Measurement System of Impedance Grounding System

\section{Experimental Results and Analysis}

\section{A. Experimental Result Data}

In these experiments, three different lengths and diameters of two layers grounding systems were designed. The lengths are 40,60, and $100 \mathrm{~cm}$ with the variation of diameters are 20, 30, and $40 \mathrm{~cm}$. The results of these measurements as the function of frequency can be seen in Table 3 . 
Table 3. Impedance and Phase angle for $\mathrm{L}=40 \mathrm{~cm}$

\begin{tabular}{|c|c|c|c|c|c|c|c|}
\hline \multirow[b]{2}{*}{ Freluensi $[H x]$} & \multirow[b]{2}{*}{ togs $F$} & \multicolumn{2}{|c|}{$1=10 \mathrm{~cm} ; \mathrm{D}=20 \mathrm{~cm}$} & \multicolumn{2}{|c|}{$\mathrm{L}=40 \mathrm{~cm} ; 0=30 \mathrm{~cm}$} & \multicolumn{2}{|c|}{$\mathrm{L}=40 \mathrm{~cm} ; \mathrm{D}=40 \mathrm{~cm}$} \\
\hline & & PHASEANGIEIOEG) & IMPEDANCE (Ohm) & PHASE ANGLE(DEG) & IMPEDANCE ( Ohm ) & PHEASE ANGLE (DEG) & IMAPEDANCE (OhIO) \\
\hline 1 & 0 & 13 & 32 & $n$ & 3a.7 & $2 \pi$ & 31.2 \\
\hline $\mathbf{1 0}$ & 1 & -54 & 47 & -53 & Was & $-5 e$ & 30 \\
\hline so & 17 & -35 & 65 & .24 & 53.8. & -36 & 35.8 \\
\hline 100 & 2 & -43.2 & 43 & -43 & 67.3 & $-4 !$ & 59.8 \\
\hline 500 & 27 & -54 & 36 & $-z$ & $m 6$ & -25 & 64.1 \\
\hline $3 \mathrm{k}$ & 3 & $-\infty . a$ & on & -48 & 57.7 & $-4 t$ & 41.2 \\
\hline \$\$ & 1.7 & -79.2 & $\pi$ & - & 52.8 & -76 & 18.1 \\
\hline $10 \mathrm{k}$ & 4 & -64.8 & ss & .53 & 6.4 & -64 & 52.4 \\
\hline sok & 4.7 & $-n$ & $8 !$ & -75 & 582 & $-n$ & 23.7 \\
\hline $100 k$ & 5 & -84.4 & $2 \pi$ & 99 & 178.8 & $-7 n$ & 93.3 \\
\hline $300 \mathrm{k}$ & i.5 & $-10,4$ & 313 & $-\infty 6$ & 111.5 & -45 & 260.5 \\
\hline $500 k$ & 5.7 & -23 & 420 & -23 & 411.7 & -35 & 3742 \\
\hline $7 \mathrm{mb}$ & 5.8 & 306 & 457 & 12 & 433.9 & 12 & $\mathrm{kNos}$ \\
\hline $1 \mathrm{M}$ & 6 & $n$ & 487 & 24 & 532.3 & 38 & 458.3 \\
\hline $2 \mathrm{M}$ & 6.3 & 15 & 678 & $n$ & 645.7 & 65 & 6262 \\
\hline $3 \mathrm{M}$ & LS & 31. & $m=0$ & 31 & 754.4 & 30 & $\pi 06.4$ \\
\hline $4 M$ & 6.6 & 52 & 643 & 55 & 016.9 & 45 & 561.4 \\
\hline $5 M$ & 6.7 & $2 \%$ & 50 & 24 & 468.6 & 67 & 409.5 \\
\hline $6 M$ & 6.8 & 11 & 438 & 34 & 423.8 & 52 & 9043 \\
\hline $7 \mathrm{M}$ & 6.85 & 26. & 356 & 45 & 324.4 & 34 & 276.4 \\
\hline$B M$ & 19 & 20 & 298 & 39 & 202.7 & 20 & $\cos 7$ \\
\hline $9 M$ & 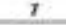 & 38 & 457 & 25 & 370.2 & 43 & 2412 \\
\hline $10 \mathrm{M}$ & 7.05 & 45 & 683 & 14 & $\operatorname{sen} 3$ & 17 & 5243 \\
\hline $12 \mathrm{M}$ & 7.1 & 35 & 753 & 27 & 725.9 & 38 & $\cos 9$ \\
\hline $1 \mathrm{AM}$ & 12 & 23 & 796 & 21 & 834.6 & 25 & 797.1 \\
\hline
\end{tabular}

- Grounding Impedance for $L=40 \mathrm{~cm}$

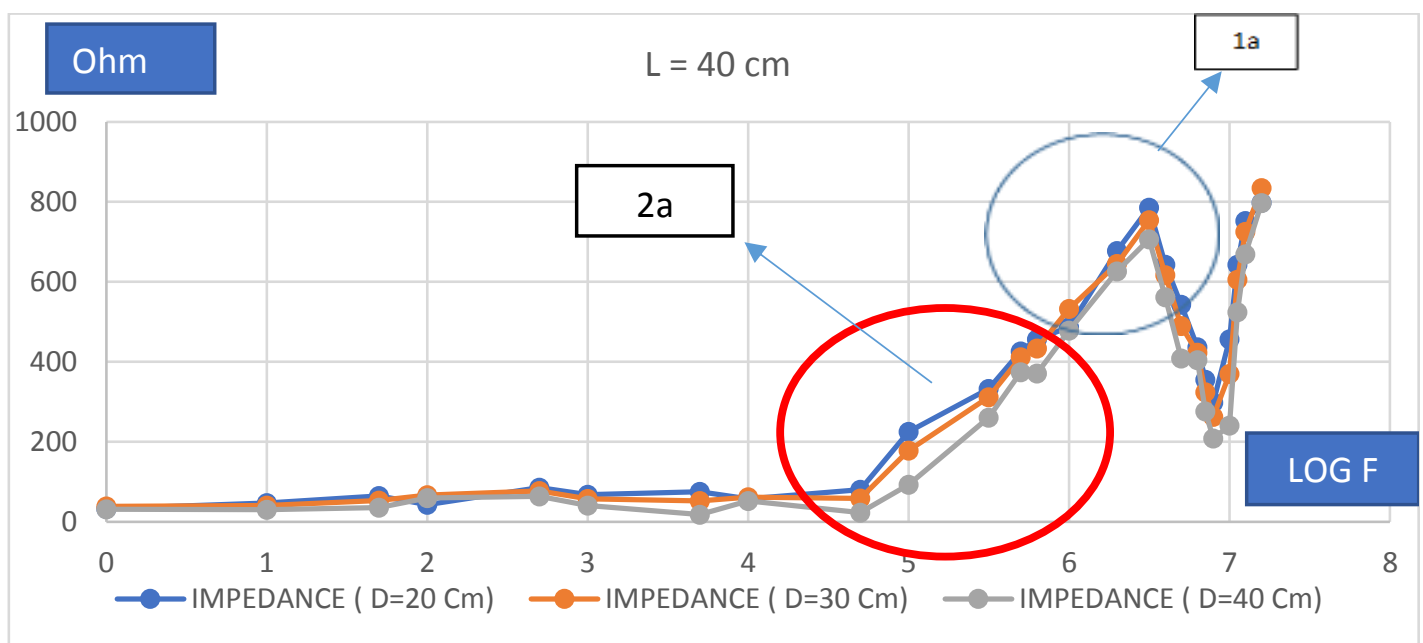

Figure 6. Grounding Impedance Vs Log Frequency for $\mathrm{L}=40 \mathrm{~cm}$

Figure 6 shows that the grounding impedance of length $(\mathrm{L})=40 \mathrm{~cm}$ only has two peaks (see blue circle 1(a), Figure 6) when tested in frequency of more than $1000 \mathrm{kHz}$. It is also identified that different sizes of diameters $(20,30$, and $40 \mathrm{~cm})$ did not resulted in different value of grounding impedance. For this condition, the "lumped" equivalent circuit can be chosen for representing grounding system such as figure 1(c) above [12]. When tested at frequency between $90-400 \mathrm{kHz}$ the grounding impedance for $\mathrm{D}=20 \mathrm{~cm}$ is bigger than $\mathrm{D}=30 \mathrm{~cm}$, and for $\mathrm{D}=30$ $\mathrm{cm}$ is bigger than $\mathrm{D}=40 \mathrm{~cm}$ (see red circle 2(a), Figure 6 . This result means, the smaller the diameter of inner layer $\left(1^{\text {st }}\right.$ layer) the higher the grounding impedance compared to the bigger diameter. Whereas, when tested in low frequency up to $100 \mathrm{kHz}$ the grounding impedance is relatively constant and the value is independent from the diameter used, the grounding impedance is the same when tested in different diameters of 20,30 , and $40 \mathrm{~cm}$. This is also the case when tested at high frequency. This phenomenon occurs when the grounding rod length is 
no more than $40 \mathrm{~cm}$. By considering the characteristic of grounding impedance and soil material compositions then the design of the grounding system can be more accurate and perfect.

The first step to analyse the results of grounding impedance and phase angle of grounding systems as the function of frequency are using dimension ratios of length to diameter (L/D) of the two layers grounding systems. Rod length is equivalent with grounding impedance inductance component, where the longer the rod the more inductive it becomes and the resistance value will be lower than the shorter rod. Soil characteristic will also affect resistivity, when first (inner) layer of rod is filled with low resistivity soil it will has lower resistance than when it filled with high resistivity soil. Therefore, in order to create lower grounding impedance of two layers system, the resistivity of the inner layer must be lower than the outer layer, in this experiment the ratio of resistivity inner / outer is 4.0, and when possible it is recommended to make the ratio of more than 10 which can be achieved by using betonite material for inner layer. Betoniteis soil material with very low resistivity.

- Phase angle for $\mathrm{L}=40 \mathrm{~cm}$

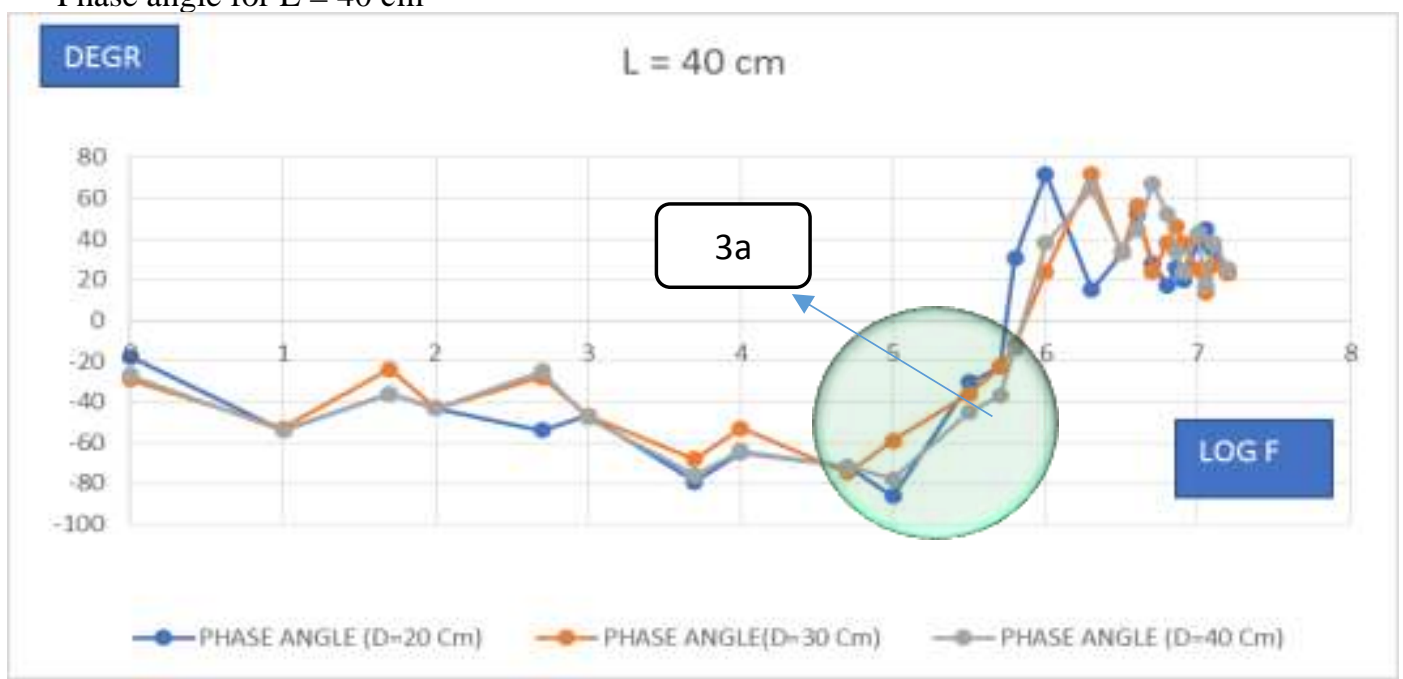

Figure 7. Phase angle Vs Log Frequency for $\mathrm{L}=40 \mathrm{~cm}$

Figure 7 shows fluctuation curves of phase angle as the function of frequency for rod with $\mathrm{L}$ $=40 \mathrm{~cm}$, it can be seen that at low frequency to several $\mathrm{kHz}$ the trend of the phase angle is capacitive or leading. The values of phase angle for $\mathrm{D}=20,30$, and $40 \mathrm{~cm}$ cannot be compared as it is similar to one another where all diameters show the same trends of gradually increasing from low to high at $\mathrm{f}=8 \mathrm{kHz}-100 \mathrm{kHz}$ and zero " 0 " at $\mathrm{f}=5-7 \mathrm{kHz}$. This frequency is known as resonance frequency and at this frequency the grounding impedance is pure resistive impedance. Above the resonance frequency the phase angle trend is to fluctuates in inductive or lagging mode, and there is some differences the phase angle values for $\mathrm{D}=20,30$, and $40 \mathrm{~cm}$. The resonance frequency for $\mathrm{D}=20 \mathrm{~cm}$ is smaller than for $\mathrm{D}=30 \mathrm{~cm}$, and for $\mathrm{D}=30 \mathrm{~cm}$ is smaller than for $\mathrm{D}=40 \mathrm{~cm}$, see circle "green" $3 \mathrm{a}$. The fluctuation of phase angle at high frequency is very difficult to predict and also it is different for $D=20 \mathrm{~cm}, D=30 \mathrm{~cm}$ and $\mathrm{D}=$ $40 \mathrm{~cm}$, sometimes the phase angle for $\mathrm{D}=20 \mathrm{~cm}$ is bigger than for $\mathrm{D}=30$ and $\mathrm{D}=40 \mathrm{~cm}$, but sometimes it is smaller. 
Table 4. Impedance and Phase angle for $\mathrm{L}=60 \mathrm{~cm}$

\begin{tabular}{|c|c|c|c|c|c|c|c|}
\hline \multirow[b]{2}{*}{ Freksensi $[\mathrm{Hz}]$} & \multirow[b]{2}{*}{ LOGF } & \multicolumn{2}{|c|}{$1=00 \mathrm{CIn} ; 0=20 \mathrm{~cm}$} & \multicolumn{2}{|c|}{$\mathrm{L}=60 \mathrm{Cm} ; \mathrm{D}=30 \mathrm{~cm}$} & \multicolumn{2}{|c|}{$\mathrm{L}=00 \mathrm{Cm}, \mathrm{D}=40 \mathrm{Cm}$} \\
\hline & & PHASE AUSLE(DEG) & IMPEOANCE ( Ohm) & PHASE AMGLE [DEG] & MPEDANCE (Ohm) & PHASE ANGLE [DEG] & IMPEDANCE (Ohum) \\
\hline 1 & 0 & -22 & 50 & -23 & 17.4 & -12 & 9.4 \\
\hline 10 & 1 & $-2 y$ & 44 & -5 & 35. & $-\Delta$ & $\Delta-1$ \\
\hline 90 & 1.7 & -54 & 50 & -56 & 30.6 & -34 & 226 \\
\hline 100 & 2 & 36 & 47 & -16 & 55.8 & -45 & 478 \\
\hline 500 & 27 & 25 & 44 & .26 & 40.4 & -42 & 35.4 \\
\hline $1 k$ & 3 & -29 & 31 & -57 & 20.8 & -30 & 15.8 \\
\hline sk & 3.7 & 54 & as & .54 & 45.4 & -54 & 35.4 \\
\hline $10 \mathrm{k}$ & 4 & -57 & 43 & -68 & 22.6 & -65 & 16.6 \\
\hline $50 \mathrm{k}$ & 4.7 & -72 & 94 & $-\infty$ & 51.5 & -72 & 27.5 \\
\hline $100 \%$ & 5 & -58 & 130 & -2 & 100.7 & $-5 t$ & 647 \\
\hline 3000 & 5.5 & -56 & 166 & -34 & 110.7 & -43 & 56.7 \\
\hline $500 k$ & 5.7 & -54 & 234 & -14 & 206.8 & -25 & 159.8 \\
\hline $700 k$ & 5.8 & -30 & 254 & 16 & 96.3 & 26 & 184.3 \\
\hline $1 \mathrm{M}$ & 6 & 12 & 354 & 36 & 320.7 & 35 & 275.7 \\
\hline $2 M$ & 6.3 & 26 & S4) & 29 & 500.6 & 29 & 424.6 \\
\hline $3 M$ & 6.5 & 35 & 654 & 15 & 599.4 & 34 & 540.4 \\
\hline $4 M$ & 6.6 & 21 & 456 & 67 & 429.8 & 63 & 393.8 \\
\hline $5 \mathrm{M}$ & 6.7 & 46 & 563 & 53 & 493.4 & 22 & 439.4 \\
\hline fim & $\mathrm{Kx}$ & 18 & 673 & $\mathrm{sA}$ & 655.5 & 18 & 627.5 \\
\hline $7 \mathrm{M}$ & 6.85 & 16 & 345 & 34 & 337.8 & 64 & 239.8 \\
\hline $8 \mathrm{M}$ & 6.9 & $2 \mathrm{~s}$ & 432 & 56 & 491.8 & 24 & 445.8 \\
\hline$O M$ & 7 & 10 & 375 & 13 & 434.8 & 37 & 31.8 \\
\hline $10 M$ & 7.05 & 48 & $45 \mathrm{~T}$ & 5 & 520,4 & 41 & 402.4 \\
\hline $12 \mathrm{~m}$ & 7.1 & 13 & 638 & 16 & $\$ 62.5$ & 53 & 476.5 \\
\hline $14 \mathrm{M}$ & 72 & 26 & 754 & 12 & 690.6 & 31 & 645.6 \\
\hline
\end{tabular}

- Grounding Impedance for $L=60 \mathrm{~cm}$

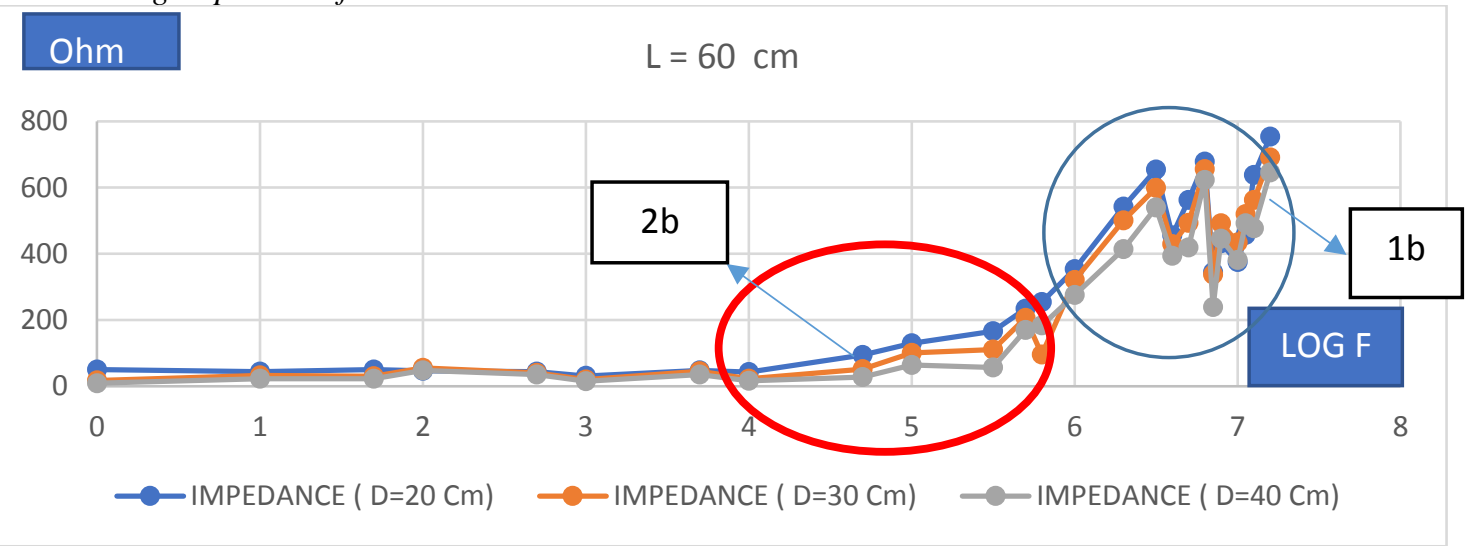

Figure 8. Grounding Impedance vs Log Frequency for $\mathrm{L}=60 \mathrm{~cm}$

Figure 8 shows that the grounding impedance with length $(\mathrm{L})=60 \mathrm{~cm}$ created three peaks (see blue circle 2a, Figure 8 at frequency more than $1 \mathrm{MHz}$ and these peaks occurs at different frequencies, therefore "lumped circuit with three types of RLC or distributed circuit such as Figure 1(c) and 1(d) above can represent the equivalent circuit. Furthermore, the value of grounding impedance for $\mathrm{D}=20 \mathrm{~cm}$ is bigger than $\mathrm{D}=30 \mathrm{~cm}$, and for $\mathrm{D}=30 \mathrm{~cm}$ is bigger than $\mathrm{D}=40 \mathrm{~cm}$. These variations start when tested in frequency $(\mathrm{f})=100 \mathrm{kHz}$ to $\mathrm{f}=10 \mathrm{MHz}$. The grounding impedance at "low" frequency to $90 \mathrm{kHz}$ relatively constant, there is no fluctuations shown and no significant difference when tested with different diameters of 20,30 , and $40 \mathrm{~cm}$. However, when compared to Figure 6, the value of grounding impedance with $L=60 \mathrm{~cm}$ is smaller than $\mathrm{L}=40 \mathrm{~cm}$ and the grounding impedance fluctuates when tested with $\mathrm{L}=60 \mathrm{~cm}$ in high frequency and very high frequency. It is crucial to design two layers grounding system and to ensure that the grounding impedance frequency is made from low to high specifically for lightning protection. 
There is very importance "thing" to design the 2 layers grounding systems to make very low at high frequency special for lightning protection [23]

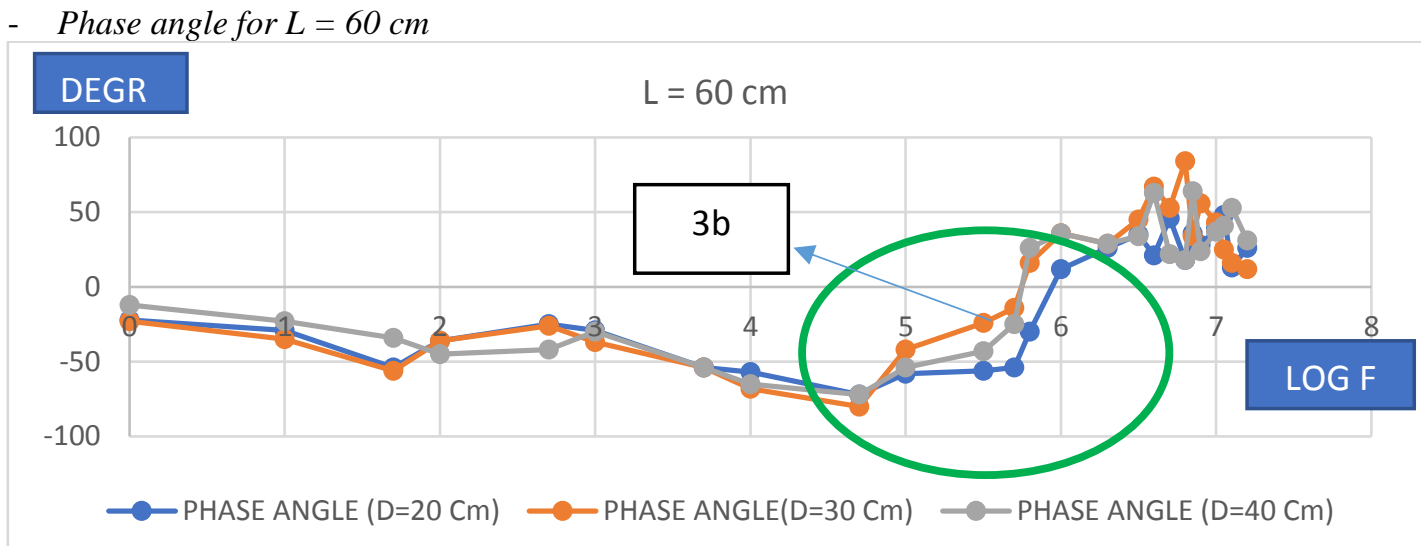

Figure 9. Phase angle Vs Log Frequency for $\mathrm{L}=60 \mathrm{~cm}$

Table 5. Impedance and Phase angle for $\mathrm{L}=100 \mathrm{~cm}$

\begin{tabular}{|c|c|c|c|c|c|c|c|}
\hline \multirow[b]{2}{*}{ Frehuensi $(\mathrm{Hz})$} & \multirow[b]{2}{*}{$106 \mathrm{~F}$} & \multicolumn{2}{|c|}{$1=100 \mathrm{~cm} ; 0=20 \mathrm{~cm}$} & \multicolumn{2}{|c|}{$\mathrm{L}=100 \mathrm{~cm}=\mathrm{D}=30 \mathrm{~cm}$} & \multicolumn{2}{|c|}{$\mathrm{L}=100 \mathrm{~cm} ; \mathrm{D}=40 \mathrm{~cm}$} \\
\hline & & PHASE ANGIFIDEG) & IMPEDANCE (Ohm) & PHASE ANGLE (DEG) & IMPEDANCE (Ohm) & PHASE ANGLE (DEG) & IMPEDANCE (Ohm) \\
\hline 1 & 0 & -15 & 35 & -15 & 35.9 & -23 & 89 \\
\hline 10 & 1 & 25 & 43 & .25 & 43.6 & 25 & 19,6 \\
\hline 50 & 1.3 & $a$ & 24 & -8 & 53.2 & -8 & 25.2 \\
\hline 100 & 7 & -10 & 45 & -18 & 5.6 & -12 & At.6 \\
\hline 500 & 27 & 29 & 35 & $\times 36$ & 35.4 & -29 & 18.4 \\
\hline $1 k$ & 3 & $-2 x$ & 33 & -92 & 5.7 & -34 & 11.7 \\
\hline $5 k$ & 1.3 & -54 & 45 & -56 & $\$ 5.3$ & -56 & 36.3 \\
\hline $10 \mathrm{k}$ & 4 & .64 & 89 & -51 & 89.6 & .62 & 54.6 \\
\hline sok & 47 & -75 & 13s & -68 & 137.4 & -75 & 98,4 \\
\hline 100t & 5 & -45 & 322 & -43 & $145 \mathrm{a}$ & -76 & ae $\mathrm{A}$ \\
\hline $300 t$ & 5.5 & $-2 n$ & 345 & -3s & 257.3 & -22 & 144,3 \\
\hline $500 t$ & 5.7 & -14 & 321 & -14 & 342.7 & -12 & 236.7 \\
\hline $700 k$ & 5.3 & -11 & $4 \pi 5$ & 10 & 457.5 & -23 & 412.5 \\
\hline $1 \mathrm{M}$ & 6 & 15 & 348 & 25 & 105.4 & 26 & $17 n A$ \\
\hline $2 \mathrm{M}$ & 6.3 & 36 & 462 & 36 & 472.2 & 43 & 345.2 \\
\hline $1 \mathrm{M}$ & 0.5 & 26 & 574 & 48 & $\operatorname{sac} 4$ & 28 & 47.4 \\
\hline $4 \mathrm{M}$ & 6.5 & 23 & 420 & 26 & 436.7 & 37 & 300.7 \\
\hline $5 M$ & 61 & 12 & 347 & 37 & 435.7 & 43 & 363.7 \\
\hline ean & 6.4 & 48 & 574 & se & $\operatorname{san} .3$ & 63 & 391.3 \\
\hline $7 \mathrm{M}$ & 6.85 & 23 & 643 & 29 & 534.2 & 51 & 522.2 \\
\hline $\operatorname{sen}$ & 69 & $3 z$ & 368 & 18 & 121.4 & 20 & 183.4 \\
\hline $9 \mathrm{M}$ & $y$ & 4s & 321 & 4s & 298.6 & 15 & 200.6 \\
\hline $10 \mathrm{M}$ & 2.05 & 34 & 475 & 26 & 378.5 & 42 & 232.5 \\
\hline $12 \mathrm{M}$ & 7.1 & 23 & 5.48 & 18 & 4528 & 13 & 258.8 \\
\hline $14 M$ & 7,2 & 14 & 622 & 30 & 573.8 & $x$ & 390.8 \\
\hline
\end{tabular}

Figure 9 shows the curves of phase angle as the function of frequency for rod with $\mathrm{L}=60$ $\mathrm{cm}$. The changes of phase angle at low frequency to $\mathrm{f}=1 \mathrm{kHz}$ is relatively small but from $\mathrm{f}=1$ $-80 \mathrm{kHz}$ the phase angle has a tendency to increase in capacitive mode. Above $\mathrm{f}=80 \mathrm{kHz}$ the phase angle tends to decrease to 500 and $700 \mathrm{kHz}$ where then the phase angle is equal to zero = " 0 ", $t$ this frequency is called as a resonance frequency. $\mathrm{D}=30 \mathrm{~cm}$ and $\mathrm{D}=40 \mathrm{~cm}$ have relatively smaller resonance frequency than $D=20 \mathrm{~cm}$, see "green" circle $3 \mathrm{~b}$. In this case there is a difference between $\mathrm{L}=40 \mathrm{~cm}$ and $\mathrm{L}=60 \mathrm{~cm}$, where $\mathrm{L}=60 \mathrm{~cm}$ have inductance value bigger than $\mathrm{L}=40 \mathrm{~cm}$, so the lagging mode occur "faster" for $\mathrm{L}=60 \mathrm{~cm}$. When tested with frequency above resonance, the phase angle for all diameters are very fluctuated and the value of phase angle cannot be predicted accurately, it is identified that for $\mathrm{D}=40 \mathrm{~cm}$ and $\mathrm{D}=30 \mathrm{~cm}$ the phase angle are bigger than for $\mathrm{D}=20 \mathrm{~cm}$ in inductive mode, it means that the grounding system with long rod have more inductance than resistance component. This fluctuation of the phase angle 
is not only affected by rod dimension but also soil characteristic that influence by its mineralogy [24]

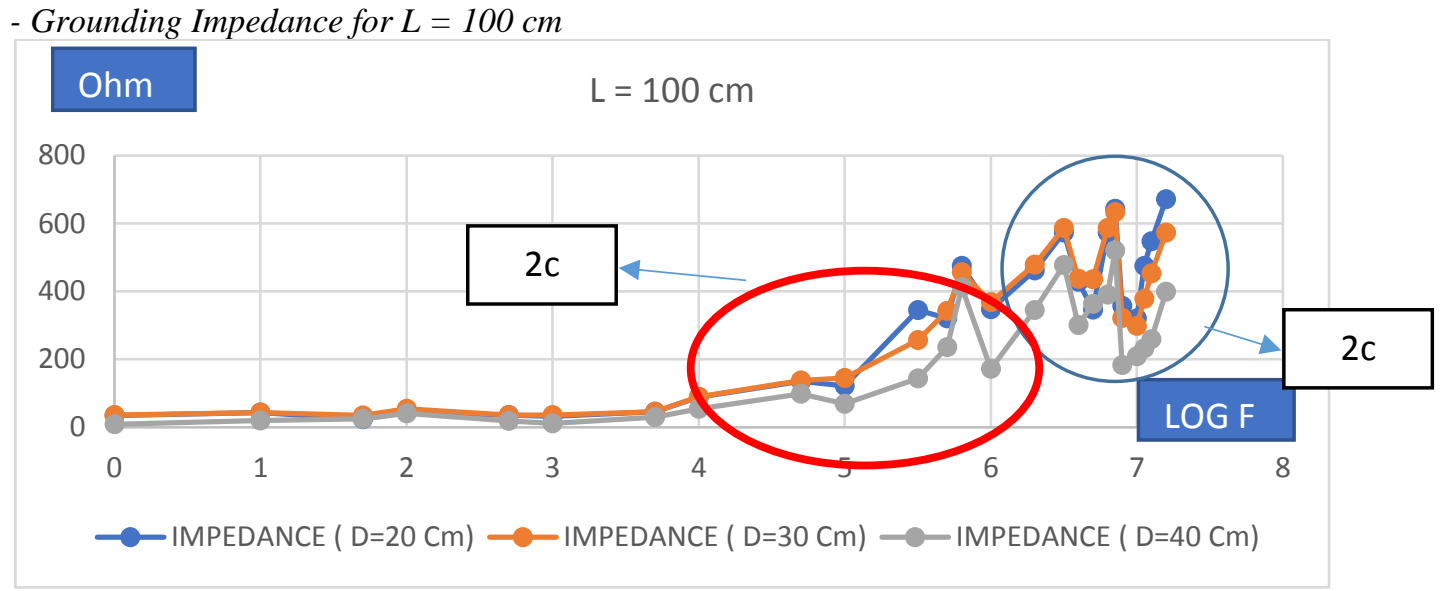

Figure 10. Grounding Impedance Vs Log Frequency for $\mathrm{L}=100 \mathrm{~cm}$

Figure 10 shows that grounding impedance for $\mathrm{L}=100 \mathrm{~cm}$ and at low frequency up until 10 $\mathrm{kHz}$ is relatively constant but at frequency of more than $10 \mathrm{kHz}$ the grounding impedance starts to increase gradually and at $\mathrm{f}=100 \mathrm{kHz}$ it increases significantly and becoming very fluctuated with around five peaks, which means that that the distributed equivalent circuit is suitable for presenting the grounding systems such as Figure 1 (d) above as stated by Dawalibi and Mukedar[12].

Different diameters of inner layer $(20,30$, and $40 \mathrm{~cm})$ does not correlated directly to the value of the grounding impedance high frequency, this is because sometimes the grounding impedance for $\mathrm{D}=40 \mathrm{~cm}$ is bigger than the $\mathrm{D}=20 \mathrm{~cm}$, and $\mathrm{D}=30 \mathrm{~cm}$ has smallest value among three diameters. When comparing between Figure 6, 8, and 10 with $\mathrm{L}=40,60$, and $100 \mathrm{~cm}$, it can be said that the grounding impedance have more peak or more fluctuated if the length is longer and the value of grounding impedance is smaller for $\mathrm{L}=100 \mathrm{~cm}$ than for $\mathrm{L}=60 \mathrm{~cm}$ and $\mathrm{L}=40 \mathrm{~cm}$. By designing the grounding system accurately, it is possible to obtained low value of grounding impedance at high frequency, by understanding well the soil characteristic and grounding system configurations. This experiment uses a grounding system with single rod and two layers of different types of soil.

From the above data, it can be seen that grounding impedance trend is to decrease at all frequencies with large diameter and long rod for the inner layer. Figure 6, 8, and 10 at circle "blue" $1 \mathrm{a}, 1 \mathrm{~b}$, and 1c shows that rod length will affect the occurrence many of peaks, where the longer the rod the more peaks it will makes, as it can be seen that with length of $40 \mathrm{~cm}$ it will creates two peaks, $60 \mathrm{~cm}$ three peaks, and $100 \mathrm{~cm}$ between four to five peaks

\section{- Phase angle for $L=100 \mathrm{~cm}$}

Figure 11 shows curves of phase angle as a function of frequency $(\log F)$ for single rod with $\mathrm{L}=100 \mathrm{~cm}$. It can be seen that at low frequency to $1 \mathrm{kHz}$ the phase angle is relatively constant with small deviation, but from $\mathrm{f}=1 \mathrm{kHz}$ to approximately $100 \mathrm{kHz}$ the phase angle increases with a constant rate and reach the maximum value in capacitive mode. Above $\mathrm{f}=100 \mathrm{kHz}$ there is clear influence of rod length to grounding impedance as there is obvious change of phase angle that decrease rapidly to zero " 0 " when $\mathrm{f}$ is between 400 to $600 \mathrm{kHz}$. The resonance frequency for $\mathrm{L}=100 \mathrm{~cm}$ and $\mathrm{D}=30 \mathrm{~cm}$ and $\mathrm{D}=40 \mathrm{~cm}$ is smaller than for $\mathrm{D}=20 \mathrm{~cm}$, see "green" circle 3c. As for high frequency of more than $1 \mathrm{MHz}$ the response of phase angle tends to be in inductive mode and constantly fluctuates at all frequencies, this fluctuation cannot be well predicted however $\mathrm{D}=40 \mathrm{~cm}$ is more inductive than $\mathrm{D}=30 \mathrm{~cm}$ and $\mathrm{D}=20 \mathrm{~cm}$. When Figure 9 , 
10, and 11 are compared it can be assumed that phase angle of grounding impedance are affected significantly by a rod length of the inductive part of grounding impedance and soil mineralogy. This experiment proves that the equivalent circuit for grounding system for high frequency is a distributed circuit, which also has been presented by Dawalibi and Mukedar [12]Please refer to Figure 7, 9, and 11 to see all of the peaks at different frequencies and above $1 \mathrm{MHz}$, circled "green" $3 \mathrm{a}, 3 \mathrm{~b}$, and $3 \mathrm{c}$.

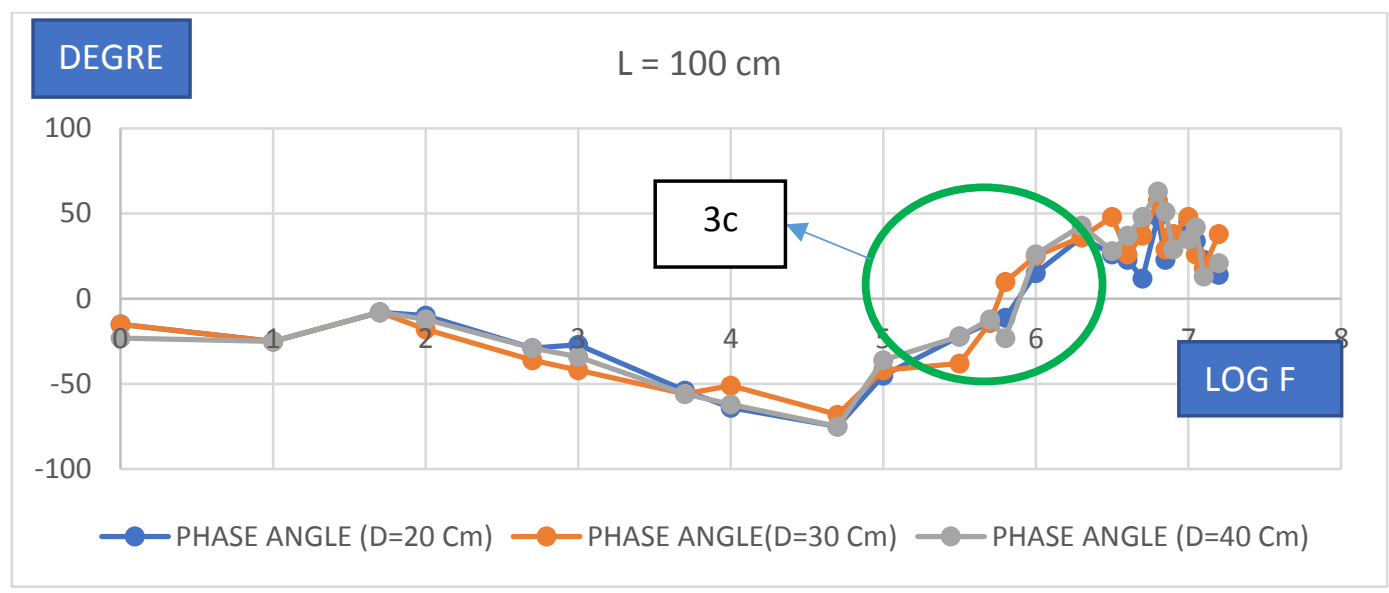

Figure 11. Phase angle Vs Log Frequency for $\mathrm{L}=100 \mathrm{~cm}$

If the grounding impedance have more than one peak it means that the value is highly dependent on the frequency which makes it difficult to predict the real value of grounding impedance. The equivalent circuit of grounding impedance of $Z=L+(R / / C)$ is not a "lumped circuit" as shown in Figure 1c but rather a "distributed circuit" as Figure 1d that have been proposed byDawalibi and Mukedar [12]. It is known that the grounding impedance $Z=Z_{1}+Z_{2}$ $+\ldots .+Z_{n}, Z_{1}=L_{1}+\left(R_{1} / / C_{1}\right) \ldots \ldots Z_{n}=L_{n}+\left(R_{n} / / C_{n}\right)$ and every segment of $Z_{(1,2 . n)}$ have one (1) resonance frequency, therefore the reason why grounding impedance at high frequency have many peaks is still in question. To date there is no experiment that has mention how to divide the total impedance $\mathrm{Z}$ into several impedance of segment $\mathrm{Z}_{1} \ldots . \mathrm{Z}_{\mathrm{n}}$ and what is the requirement to make equivalent impedance to be "lumped" or "distributed" including the ratio of dimension or ratio of resistivity and permittivity of soil. All of these conditions are caused by the grounding configuration and material conditions.

If the analysis of soil material components, porosity, water content be done accurately and the configuration can be defined well then it is possible to predict the "real" value of grounding impedance at many frequencies. During this experiment the resonance frequency occurs at about $400-800 \mathrm{kHz}$ as stated in equation 15 above, and the value of grounding impedance equal to the resistance $(Z=R)$. However, at high frequency the grounding resistance is higher than when at low frequency. The reason why this condition occurs in this experiment is because at high frequency resonance the permittivity of soil has $\varepsilon$ " which is in the same direction of resistance (Cole-Cole diagram) see figure 3 and equation (20), therefore it will add to the value of the resistance of grounding impedance.

\section{Conclusion}

This paper reports the modification of a grounding system with vertical layers configuration. This is the novel issue because the other researchers use horizontal layers configuration. In this experiment, the grounding rod is injected by using low to high frequency AC source The modification is made by filling the soil into a grounding rod (cylinder rod) and therefore it created two soil layers of grounding system, and by using three size variations of cylindrical layers of length (L) of 40, 60, and $100 \mathrm{~cm}$; and three size variations of diameter (D) of 20,30, and $40 \mathrm{~cm}$. These variations allow us to understand the characteristic of the grounding impedance at low and 
high frequency, where usually the composition of inner layer soil have lower resistance than the outer soil. The composition of the outer soil consist of $16.85 \%$ clay, $66.18 \%$ silt, $15.48 \%$ sand, and $1.49 \%$ gravel whereas the composition for the inner/filling soil consist of $34.98 \%$ clay, $49.55 \%$ silt, $15.35 \%$ sand, and $0.16 \%$ gravel. The experiment results are concluded as follows: The value of soil permittivity and resistivity affect the value of grounding impedance at low and high frequency.

The grounding impedance was plotted as the function of the frequency and until now the value of this fluctuation cannot be determined accurately.

The grounding impedance at high frequency is different than one at low frequency. In general, the results indicated that the grounding impedance at high frequency was higher than at low frequency, but the fluctuation of grounding impedance depended on the condition of inner soil, length and diameter of cylindrical rod.

The grounding impedance depends on the frequency of the current injection, dimension of the rods, and the mineralogy of the soil.

The fluctuations of grounding impedance are caused by the configuration and component material of the soil especially at high frequency of more than $500 \mathrm{kHz}$.

The curve of impedance of grounding system using rod with length (L) of $100 \mathrm{~m}$ and diameters (D) of 20,30, $40 \mathrm{~cm}$, has many peaks of around $4-5$ peaks, so the equivalent circuit for this condition is the "distributed circuit".

To predict the grounding impedance accurately, the component of soil material must be identified accurately, and have to be tested using different grounding system variable.

It is recommended that the research to better understand grounding system characteristic for high frequency must be continued.

\section{References}

[1]. Blattner C.J, Prediction of Soil Resistivity and Ground Rod Resistance Deep Ground Electrodes, IEEE Transaction Apparatus and System Vol PAS 99, No 5 Sept / Oct 1980.

[2]. Anggoro, B., Sinisuka, N.I., Pakpahan, P.M., Irman, Dicky B. The Physical Treatment Soil Characteristics for Grounding Systems on Madiun and Surabaya Regions. Majalah IPTEKVol. 18, No. 1. 2007.

[3]. Anggoro, B., Irman, D.B. The Characteristics of Soil which is Treated by Salt Solution and Water as The Basic of Grounding Diagnostics. Bali. IEEE International Conference on Condition Monitoring and Diagnosis. 2012.

[4]. Dick W., dan Holiday H.R, Impulse and Alternating Current Test on Grounding electrodes in Soil Environment, IEEE Transaction on Power Apparatus and Systems Vol PAS 97, No 1 Jan / Feb.1978.

[5]. Anggoro, B. The Concept of Grounding Impedance Diagnostics Method. Bali. IEEE International Conference on Condition Monitoring and Diagnosis. 2012.

[6]. Anggoro, B., Sinisuka, N.I., Pakpahan, P.M. The Influence of Resistivity and Dielectric Constant of Soil Which is Injected by Low to High Current Frequency. 2006.

[7]. G.F. Tagg. Earth Resistances. London: George Newnes Limited. 1964.

[8]. IEEE Std 81TM-2012 Guide for Measuring Earth Resistivity, Ground Impedance, and Earth Surface Potentials of a Grounding System.

[9]. IEEE Std 142TM-2007 Grounding of Industrial and Commercial Power Systems.

[10]. IEEE Std 81.2-1991, "IEEE Guide for Measurement of Impedance and Safety Characteristics of Large, Extended or Interconnected Grounding Systems Sponsor", Approved December 5, 1991.

[11]. F. Dawalibi, Mukhedkar D, Multi Step Analysis of Interconnected Grounding Electrodes, IEEE transactions on Power Apparatus and Systems, Vol. PAS 95 No 1, Jan / Feb 1976

[12]. F. Dawalibi, C.J. Blattner. Earth Resistivity Measurements Interpretation Techniques. IEEE Transactions on Power Apparatus and Systems, Vol. PAS-103, No. 2. 1984.

[13]. Dawalibi F, danMukhedkar D, Ground Electrode Resistance Measurements in Non Uniform Soils, IEEE Transactions on Power Delivery, Vol PAS-103 No 2 February, 1984. 
[14]. L. Grcev, M. Popov, On High-Frequency Circuit Equivalents of a Vertical Ground Rod. IEEE Transactions on Power Delivery, Vol. 20, No. 2, 2005.

[15]. Pelton, W.H., Ward, S.H., Hallof, P.G., et al.: 'Mineral discrimination and removal of inductive coupling with multifrequency IP', Geophysics, 1978, 43, (3), pp. 588-609

[16]. Han, Y., Misra, S.: 'A unified inversion scheme to process multifrequency measure- ments of various dispersive electromagnetic properties', J. Appl. Geophys., 2018, 151, pp. 23-39

[17]. Garc'lła-Fiscal, S., Flores, C.: 'Sensitivity of galvanic and inductive Induced Polar- ization methods to the Cole-Cole parameters', J. Appl. Geophys., 2018, 158, pp. 1-10

[18]. Jaggar, S.R., Fell, P.A., Jaggar, S.R., et al.: 'Forward and inverse Cole-Cole modelling in the analysis of frequency domain electrical impedance data', ExplorGeophys., 1988, $19,(3)$, pp. 463-470

[19]. M. Akbari, K. Sheshyekani, F. Rachidi, C.A. Nucci et al A Full-Wave Analysis of Lightning -Induced Voltage on Distribution Lines Considering the Conductive Coupling between the Lightning Channel and the Grounding Systems, 2012 International Conference on Lightning Protection (ICLP) Vienna Austria.

[20]. Reynolds J.M, An Introduction to Applied and Environmental Geophysics, John Wiley and Sons, 1997.

[21]. B.R. Gupta and B. Thapar, "impulse impedance of grounding grids", IEEE trans. On power apparatus and systems vol. PAS-99.2357-2362, 1980.

[22]. C.J. Blattner. Analysis of Soil Resistivity Test Methods in Two-Layer Earth. New York: IEEE Transactions on Power Apparatus and Systems, Vol. PAS-104, No. 12, 1985.

[23]. O.P. Rahi, Abhas Kumar Singh, Shashi Kant Gupta, Shilpa Goya, "Design of Earthing System for a Substation", (ISSN (print): 2249-7277 ISSN (online): 2277-7970) Volume2 Number-4 Issue-6 December-2012

[24]. Ke TANG, Jiangjun RUAN, Daochun HUANG et al, Application Study of Flexible Graphite Grounding Electrode in Typical Tower Grounding Grid, 978-1-5090-04966/16/531.00, 2016 IEEE 


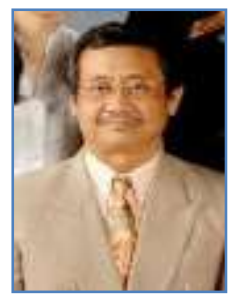

Bambang Anggoro was born in Madiun, East Java, on February, 15, 1955. Hereceiveda Electrical Engineer, Master and Doctor degree in 1979, 1990 and 2006 Hisresearches are Electromagnetics, Bio electromagnetics and grounding systems. Since 1980 he has been a lecturer in High Voltage and High Current Laboratory, Electrical Power Engineering Division of STEI - ITB.

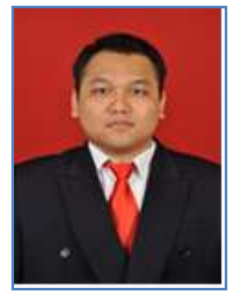

Rio Hakim Dharmawanwas born at Magelang, July 8, 1989, He received Bachelor Degree in Electrical Engineering from Telkom Institute of Technology, Bandung, in 2012.and Master Degree from Bandung Institute of Technology, in 2014. He joined Airport Technology Network Operation and Support Technician, Sultan Aji Muhammad Sulaiman International Airport, Sepinggan Balikpapan, 2015.

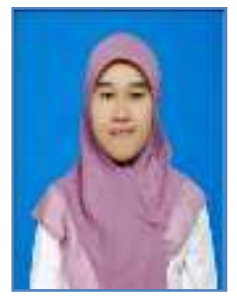

Hanifah Nur Kumala Ningrum was born at Madiun, Indonesia, November $26^{\text {th }}$ 1988. She received Bachelor Degree in Electrical Engineering from ITS Surabaya and Master Degree from Bandung Institute of Technology, in 2011 and 2014.She joined Diploma Degree on Electric Engineering, Engineering Department, State Polytechnic of Madiun (Politeknik Negeri Madiun) in 2015 as a lecturer. Her teaching and research responsibility involve power systems, power electronics and renewable energy.

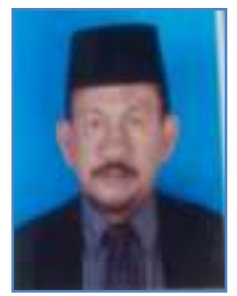

Junaidy Burhan was born in July 31, 1957 at LubukLinggau, South Sumatera-Indonesia He rreceived Bachelor Degree in Electrical Engineering fromSriwidjaja University Palembang,in 1983, Master Degree from Bandung Institute of Technology, in 1990 and Doctorate in Regional Planning Program, University of Sumatra Utara , 2015. , active in Board of Indonesia Engineer (Persatuan Insinyur Indonesia, PII) as vice director on International Monitoring Committee (IMC) . Dean Faculty of Engineering and Industrial Technology at Politeknik Enjinering Indorama Purwakarta as Associate

Professor

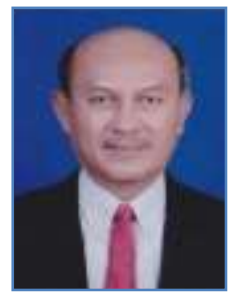

Mohamad Rom bin Tamjis was born in April 6, 1956 . He rreceived Bachelor Degree in Electrical Engineering from Southampton University England in 1980, Master Philosophy from Southampton University England in 1982 and DoctoratePhilosophy from Newcastle University England in 1992. Professor in Electrical Engineering and as Dean at Department of Electrical Engineering, Faculty of Engineering University of Malaya since 2004.More than 21 International papers have been written since 1980 until now. 